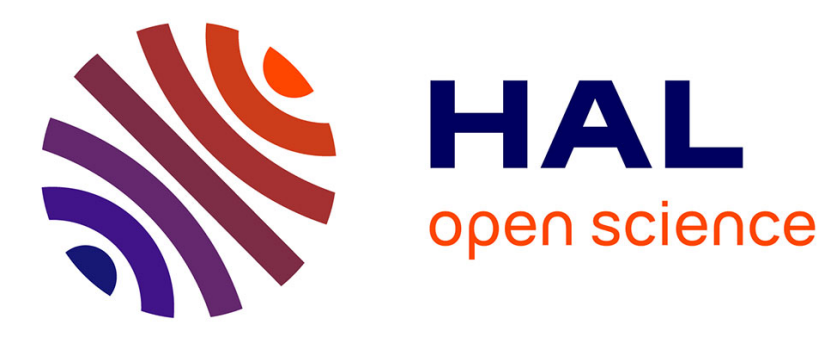

\title{
The Dialogical Dimension of Intonational Meaning: Evidence from French
}

Cristel Portes, Claire Beyssade, Amandine Michelas, Jean-Marie Marandin, Maud Champagne-Lavau

\section{- To cite this version:}

Cristel Portes, Claire Beyssade, Amandine Michelas, Jean-Marie Marandin, Maud Champagne-Lavau. The Dialogical Dimension of Intonational Meaning: Evidence from French. Journal of Pragmatics, 2014, 74, pp.15-29. 10.1016/j.pragma.2014.08.013 . hal-01485956

\section{HAL Id: hal-01485956 https://hal.science/hal-01485956}

Submitted on 22 Jul 2021

HAL is a multi-disciplinary open access archive for the deposit and dissemination of scientific research documents, whether they are published or not. The documents may come from teaching and research institutions in France or abroad, or from public or private research centers.
L'archive ouverte pluridisciplinaire HAL, est destinée au dépôt et à la diffusion de documents scientifiques de niveau recherche, publiés ou non, émanant des établissements d'enseignement et de recherche français ou étrangers, des laboratoires publics ou privés. 


\title{
The dialogical dimension of intonational meaning: Evidence from French
}

\author{
Cristel Portes ${ }^{\mathrm{a},{ }^{*}}$, Claire Beyssade ${ }^{\mathrm{b}}$, Amandine Michelas ${ }^{\mathrm{a}}$, \\ Jean-Marie Marandin ${ }^{\mathrm{C}}$, Maud Champagne-Lavau ${ }^{\mathrm{a}}$ \\ a Aix Marseille Université, CNRS, LPL UMR 7309, 13100 Aix-en-Provence, France \\ b Institut Nicod, CNRS-ENS-EHESS, Pavillon Jardin, Ecole Normale Supérieure, 29, rue d'Ulm, F-75005 Paris, France \\ ' Université Paris Diderot, CNRS, LLF, UMR 7110, Case Postale 7031 - 5, rue Thomas Mann, F-75205 Paris Cedex 13, France
}

Received 7 February 2014; received in revised form 26 August 2014; accepted 29 August 2014

\begin{abstract}
The aim of this study was to test if the meaning of intonational contours involves speaker commitment and attitude attribution to the addressee. We examined whether the pragmatic choice of a contour signals how the speaker (S) anticipates the reaction of the addressee (A) to his utterance by attributing attitudes to him and calling for his next move. We focused on four French contours (a fall $\mathrm{L}^{*} \mathrm{~L} \%$, a rise $\mathrm{H}^{*} \mathrm{H} \%$, a rise-fall $\mathrm{H}^{*} \mathrm{~L} \%$ and a rise-fall-rise $\mathrm{H}+! \mathrm{H}^{*} \mathrm{H} \%$ ). In an original forced-choice interpretation task, participants heard sentences carrying one of the contours and had to choose among four possible reactions chosen for their hypothetical link to the contour meanings (I get it; I've no idea; I guess you're right; No, really, it's true). The results show that $L * L$ was consistently associated with "I get it", confirming that $A$ did not know proposition $\mathrm{p}$ before and signaling that $\mathrm{p}$ was added to the common ground, $\mathrm{H}^{*} \mathrm{H} \%$ with "I've no idea", which rejects S's attribution to $\mathrm{A}$ of knowledge about $\mathrm{p}$, and $\mathrm{H}+\mathrm{l} \mathrm{H}^{*} \mathrm{H} \%$ with "No, really, it's true", which signals that A actually believes p while S does not. They give experimental support to the view that intonational meaning is dialogical.
\end{abstract}

(C) 2014 Elsevier B.V. All rights reserved.

Keywords: Intonation; Intonational meaning; Commitment; Attribution of attitudes; Dialogue; French

\section{Introduction}

Intonation is known to convey pragmatic meaning. Specifically, this meaning has often been related to various aspects of speech acts. The types of claims documented can be broken down into three categories: the first conceives intonational meaning as an expression of the epistemic attitude of the speaker; the second introduces the dialogical notion of commitment; and the third extends the inventory of relevant dialogical attitudes at work in intonational meaning.

Thus, the first recurring claim about intonation is that it conveys various epistemic attitudes on the part of the speaker toward the content of his/her utterance, such as certainty or doubt. For instance, in their study of English intonation, O'Connor and Arnold (1973) distinguished a high fall nuclear tone conveying "impressed" or "challenging" attitudes from a low fall expressing "disapproval" or "reassurance". Liberman and Sag (1974) "contradiction" contour was reinterpreted

\footnotetext{
* Corresponding author at: Laboratoire Parole et Langage, 5 Avenue Pasteur, BP 80975, 13604 Aix-en-Provence, France. Tel.: +336130480 50; fax: +33413553744.

E-mail addresses: cristel.portes@Ipl-aix.fr, christelle.portes@univ-amu.fr (C. Portes), claire.beyssade@ehess.fr (C. Beyssade), amandine.michelas@blri.fr (A. Michelas), marandin@linguist.univ-paris-diderot.fr (J.-M. Marandin), maud.champagne-lavau@lpl-aix.fr (M. Champagne-Lavau).
} 
as conveying speaker uncertainty by Ward and Hirschberg (1985). Concerning the intonation system of French, Delattre (1966) proposed that the rising-falling contour that he called "implication contour" expresses obviousness in some contexts, exasperation, or on the contrary, politeness in others; and Mertens (2008) attributed the expression of "obviousness" to a contour that falls to the bottom of the pitch range. However, these accounts suffer from two main problems: (i) the different meanings attributed to contours are not clearly defined and (ii) their association with specific contours is too vague, to the extent of appearing excessively context dependent.

Several authors have proposed standardizing the various attitudes using the concept of "commitment", which refers to how much the speaker presents himself/herself as supporting the truth of the content of his/her utterance despite possible contention on the part of the addressee (Bartels, 1997; Gunlogson, 2003, 2008). Commitment is therefore a dialogical attitude of the speaker who projects the addressee's potential reaction to his/her move. Hence, several authors have underlined the role of the addressee in intonational meaning: Gunlogson $(2003,2008)$ associated the falling contours in declarative sentences in English with commitment on the speaker's behalf (S) but rising contours with commitment on behalf of the addressee (A). Steedman (2007) recast this idea, claiming that rising contours rather convey the "attribution" of commitment to $A$ on the part of $S$. The commitment approach has the advantage of conceiving intonational meaning in a more systematic way. The hypothesis that the meanings of contours are organized in a coherent structured system has also been developed (Gunlogson, 2003, 2008; Steedman, 2007). However, the notion of commitment may not in itself be enough to cover the variety of intonational meanings in different languages.

Other dialogical attitudes have thus been proposed to account for intonational meaning. For instance, Merin and Bartels (1997) proposed that some contours convey dominance relationships between interlocutors. Redefining discourse acts, Beyssade and Marandin (2006) proposed a unified account of four contours in French, assuming that they represented the main types of contour in the prosodic grammar of French. They claimed that the contours essentially signal how the speaker projects the reception of his/her utterance given the current state of the conversation. Their meaning includes both clues as to the actual commitment of the speaker and to the attitudes the speaker attributes to the addressee. Thus, borrowing an idea from Truckenbrodt (2004), Beyssade and Marandin (2006) added another dimension to intonational meaning, which they referred to as "call on addressee". This notion refers to a request from $S$ concerning A's next move: for instance, a question requires an answer for its next move, an assertion requires an acknowledgment, etc. Both attributions of commitment and call on addressee give more theoretical ground for a dialogical approach of intonational meaning including a representation of the addressee in the meaning definition.

In this study, we focused on declarative sentences, and we did not address the issue of sentences that have interrogative or jussive syntactic constructions. Building on the idea that intonational pragmatic meaning is crucially dialogical and conveys S's commitment, the attribution of attitudes to A by S, and S's call on A, our study aimed at determining experimentally whether intonational contours express $S$ 's attitude toward the relation of her utterance and the common ground being locally under construction in the ongoing interaction. After presenting the model of intonation and the type of intonational data we used in this study (section 2), this paper details the notions of commitment, attitude attribution and call on addressee and their relationship to intonational meaning, as developed in the literature (section 3). In the second part of the paper (section 4), we describe an original forced-choice interpretation task in which participants have to choose among four possible reactions reflecting how they would react if the speaker were addressing them and given the attribution of attitude to them by the speaker, inherent in the contour used by the speaker. A discussion of the results and their implications for a dialogical view of intonational meaning, anchoring it in an interactional context follows (section 5). We then go on to conclude and outline a number of perspectives (section 6).

\section{Intonational background}

Intonation refers to what is perceived as the melody and the rhythm of spoken language. Intonational phonology defines it as "the use of suprasegmental phonetic features to convey 'postlexical' or sentence-level pragmatic meanings in a linguistically structured way." (Ladd, 2008:6). Intonation operates with four acoustic parameters of speech: fundamental frequency (f0), loudness, length of syllables and voice quality. Intonational contours (or tunes) are continuous pitch movements associated with utterances. Following the autosegmental-metrical framework (AM) adopted here, contours are conceived as tonal movements, made up of a combination of different kinds of tones - each tone being either high $(\mathrm{H})$ or low $(\mathrm{L})$. Some of them are associated with prominent syllables (metrically strong syllables). These are referred to as pitch accents and are coded $T^{*}$. Other tones mark the edges of prosodic constituents of different levels: at the edge of the intermediate phrase (ip), they are called phrasal tones and are coded T-; at the end of the larger intonational phrase (IP), these are referred to as boundary tones and are coded T\%.

In French, contrarily to what happens in other Romance languages such as Italian or Spanish, prominent syllables associated with pitch accents are not lexically defined. The accented syllable is the last full syllable (i.e. different from a 


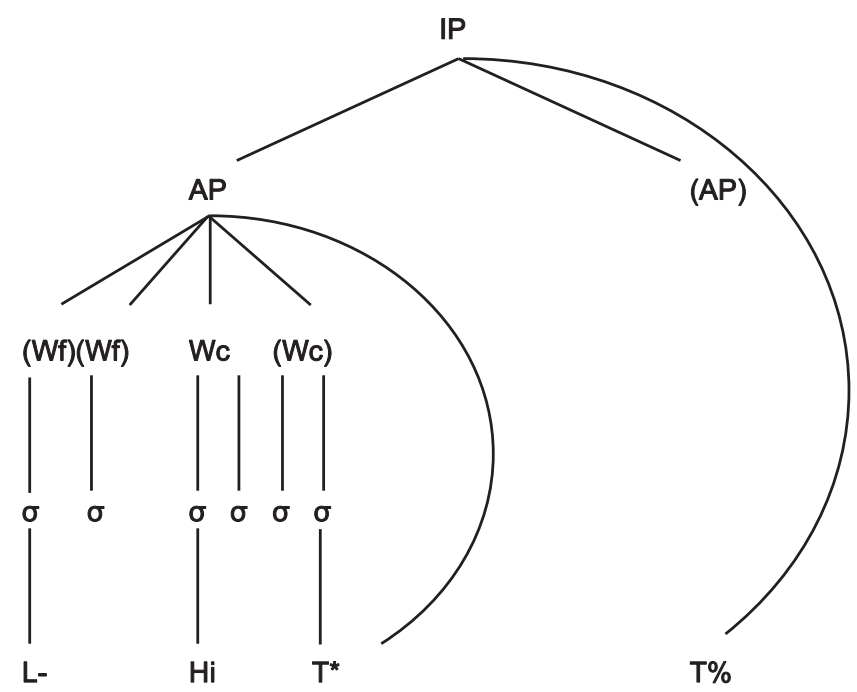

Fig. 1. French intonational structure of the intonational phrase (IP) and the accentual phrase (AP). Adapted from Jun and Fougeron (2000).

syllable whose nucleus is a schwa) of a prosodic domain called Accentual Phrase (AP), which is lower than the ip and the IP in the prosodic hierarchy. In other words, accent in French is defined at a phrasal level rather than lexically. ${ }^{1}$

Since the intonational contours under study here are compositions of pitch accents and boundary tones, they are associated with the IP level, as illustrated in Fig. 1 (adapted from Jun and Fougeron, 2000).

Fig. 1 shows that $\mathrm{T}^{*}$ is associated with the last syllable of the AP while T\% is associated with the right edge of the IP. The edge tone L- on the first function word (Wf) of the AP and the high tone Hi occurring on the first syllable of the first content word (Wc) form the optional initial rise. Many authors have referred to this as "accent d'insistance" (emphatic stress) (among others Grammont, 1933; Martin, 1975; Rossi, 1980; Dell, 1984; Mertens, 1990), and it has been claimed that it plays a role in information structure marking (German and D'Imperio, 2010; Beyssade et al., 2011). Since the initial rise is independently controlled and does not generally involve the shaping of the contour we will have nothing further to say about it in the rest of the paper.

Various combinations of pitch accents $T^{*}$ and boundary tones T\% form the IP final contours in French. The four that were used in this study were chosen because they have already been well documented: a simple fall $L^{*} L \%$, a simple rise $\mathrm{H}^{*} \mathrm{H} \%$, a rise-fall on the last syllable $\mathrm{H}^{*} \mathrm{~L} \%$, and a rise-fall-rise with the f0 peak on the penultimate syllable $\mathrm{H}^{+} \mathrm{H}^{*} \mathrm{H} \%$. Note that in the latter contour, the pitch accent $\mathrm{H}+\mathrm{H}^{*}$ is bitonal: it is composed of an $\mathrm{H}$ leading tone on the penultimate syllable of the IP, followed by a downstepped ! $\mathrm{H}^{*}$ tone on the last syllable. The diacritic '!' in '! $\mathrm{H}$ ' signals that the high tone $\mathrm{H}$ is phonetically implemented lower in the speaker range than the preceding $\mathrm{H}$ tone. The tone bearing the star ' $\mathrm{T}^{\star \prime}$ ' is the one that is aligned with the accented syllable. Four renderings of the utterance 'Jules a engagé un ingénieur' (Jules hired an engineer), illustrating the four contours under investigation, are given in Fig. 2.

These four contours have been identified and described in the literature on French intonation, even if these descriptions are neither systematic nor always exactly the same. The $L^{*} L \%$ contour is represented by a simple fall to the bottom of the speaker range. It corresponds to Delattre's (1966) "intonation de finalité" ( finality intonation) or Rossi's (1981) "intonème conclusif" (conclusive intonation). It is widely used in assertoric declaratives and wh-interrogatives (Delattre, 1966; Vaissière, 1980; Di Cristo, 1999; Post, 2000; Mertens, 2008). The $\mathrm{H}^{*} \mathrm{H} \%$ contour is a simple rising movement, which may correspond either to Delattre's "continuation majeure" (major continuation) or to "question" (question intonation). These two uses have never been shown to rely on clear differences in the form of the contour, although it has often been suggested (Faure, 1973; Rossi, 1981; Leon, 1992). Here, we focus on the questioning meaning of $\mathrm{H}^{*} \mathrm{H} \%$ : it has been established that a declarative sentence with an $\mathrm{H}^{*} \mathrm{H} \%$ contour can be interpreted as a questioning move (Beyssade and Marandin, 2007; Portes and Beyssade, in press). The $\mathrm{H}^{\star} \mathrm{L} \%$ contour is a rising-falling movement realized mostly on the last syllable of the utterance or its focused constituent. It corresponds to Delattre's "intonation d'implication" (implicative intonation). As for its meaning, this contour has been said to convey obviousness, expressiveness, and to trigger inferences

\footnotetext{
${ }^{1}$ This characteristic, which French shares with other languages, makes some specialists of French intonation reject the existence of pitch accents in this language (Rossi, 1980; Vaissière, 1983; Féry, 2001, 2013). Conversely, following Jun and Fougeron (2000, 2002) and Post (2000) among others, we will adopt an AM approach for French intonation allowing for pitch accents and boundary tones.
} 


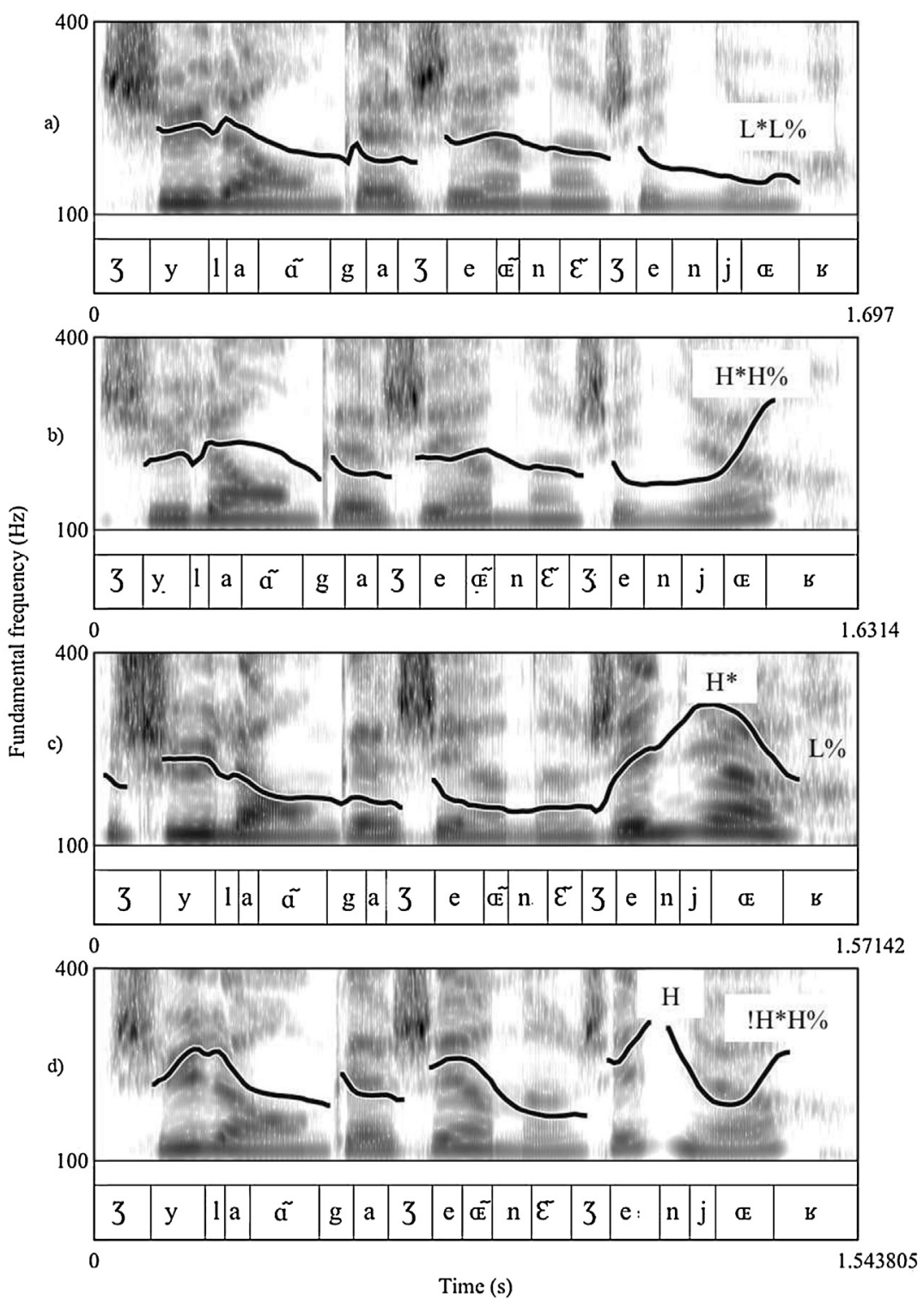

Fig. 2. Four renderings of the Utterance 'Jules a engagé un ingénieur' Jules hired an engineer with the four IP Final Contours: (a) $L^{*} L \%$; (b) $H^{*} H \%$, (c) $\mathrm{H}^{*} \mathrm{~L} \%$ and (d) $\mathrm{H}+$ ! $\mathrm{H}^{*} \mathrm{H} \%$.

(Rossi, 1999; Martin, 1975; Delattre, 1966, respectively). More recently, Portes and Reyle (2014) showed that the various meanings taken by this contour in conversation can be subsumed under a presupposition of contrast, given by a contextually relevant set of alternatives to the proposition p conveyed by the utterance. Finally, the $\mathrm{H}+! \mathrm{H}^{*} \mathrm{H} \%$ contour belongs to a group of contours, which present a leading $\mathrm{H}$ tone on the penultimate syllable of the utterance. According to Dell, one of these contours "presents [the sentence] as an incredulous or disapproving reply to someone else's statements" (Dell, 1984:66, cited and translated by Ladd, 2008:120). Indeed $\mathrm{H}+! \mathrm{H}^{*} \mathrm{H} \%$ has been experimentally elicited in contexts expressing incredulity (Michelas et al., in press). In section 4.2 below, we elaborate the meanings currently attributed to the four contours in detail, using the pragmatic notions of commitment, attitude attribution and call on addressee.

\section{Commitment, attitude attribution and call on addressee}

As mentioned in the introduction, a fruitful alternative to the attitudinal approach of contours' meaning has been developed through the use of the notion of commitment in the intonational literature (cf. Beyssade and Marandin, 2009 for a recent survey). Hamblin $(1970,1971)$ first introduced this notion into formal approaches to dialogue and argumentation. 
Commitment refers to a dialogical attitude of the speaker (henceforth $\mathrm{S}$ ) with regards to the content of his/her assertion (other speech acts are not considered in Hamblin's proposal): in a language exchange conceived as a game, asserting consists in making public that $S$ is ready to support the asserted content despite potential contention on the part of his/her addressee (henceforth $\mathrm{A}$ ): the dialogical aspect of commitment is therefore emphasized. Another important property of a commitment is that it is compatible with any propositional attitude (belief, desire or intention). In sum, commitment can be defined as a publicized engagement toward some content (its truth for assertion, but see Gazdar (1981) and Beyssade and Marandin (2006) for a generalization on other speech acts). In the intonational literature, one finds an early use of the notion of commitment in Gussenhoven's (1983) extensive reflexion about intonational meaning: the simple rise in British English is said to signal that $S$ is NOT committed to the content of his/her utterance. This explains why it is a basic marker of a question. More recently, Gunlogson $(2003,2008)$ proposed an important innovation in the use of the notion, introducing not only S's commitment but also that of A. In her view, American English falling contours, typically used in assertions, signal S's commitment to the truth of the proposition $p$ conveyed by the sentence. Conversely, rising contours, typically used in confirmation questions, signal A's commitment to it, since A is asked to say whether $p$ is true or not. However, the idea that a commitment of A can be conveyed by S's choice of one contour contradicts the idea that a commitment is crucially an attitude of the speaker, even if it is a dialogical one. Steedman's (2007) rewording makes Gunlogson's intuition in keeping with the original definition: English rising contours rather signal the attribution of that commitment to $\mathrm{A}$ on behalf of $\mathrm{S}$. The dialogical aspect of commitment thus becomes more explicit.

In studies on intonation, Brazil's $(1975,1978)$ notion of "discourse intonation" converges interestingly with the commitment trend, which comes from semantic/pragmatic studies. Brazil claims that not only $S$ but also $A$ and their shared knowledge as attributed to A by S play a crucial role in the choice of intonation contours. For instance, "referring tones" differ from "proclaiming tones" because the former only evoke background information while the latter "project an assumption that the matter is not yet accommodated in the hearer's world" (Brazil, 1985:66). This proposal is to be seen together with the prosodic marking of information structure, specifically the given/new dimension: see Hirschberg (2003) and Baumann (2006) for recent overviews and proposals from the intonation side of the literature on this issue. The view that intonational meaning refers to shared knowledge or "common ground" is also largely and fruitfully developed in further intonational literature. Pierrehumbert and Hirschberg (1990) thus claimed that the choice of a tune in American English conveys "a particular relationship between an utterance, currently perceived beliefs of a hearer or hearers $(H)$, and anticipated contribution of subsequent utterances" (underlining is ours). Similarly, Ward and Hirshberg's joint work on the meaning of different tunes (Ward and Hirschberg, 1985; Hirschberg and Ward, 1992, 1995) refers explicitly to Grice's Cooperative Principle (Grice, 1975) and to Clark's conception of mutual knowledge (Clark et al., 1981; Clark, 1992, 1996). In different Romance languages, the choice of a pitch accent has been said to reflect "the degree of confidence with which the speaker believes the information to be shared with the interlocutor" (Grice and Savino, 1997:29, see also Vanrell et al., 2013 for a recent survey).

The model of intonational meaning for French elaborated by Beyssade and Marandin (2007) has the advantage of explicitly articulating the two notions introduced above: commitment and attitude attribution, and adds a third dimension to contour meaning: call on addressee. The latter notion is borrowed from Truckenbrodt (2004). Beyssade and Marandin defined it as follows: "utterances have two types of impact on the dialogical context. On the one hand, they bring about a new commitment for Speaker; on the other hand, they call on Addressee for him to take up the utterance. (...) For instance, demands for confirmation, i.e. questioning declaratives, can be analyzed as committing Speaker to their propositional content on the one hand and, on the other hand, calling on Addressee for him to take up the utterance as a question (equivalent to a polar question)" (Beyssade and Marandin, 2006:37-38). In a recent paper, Krifka (in press) analyzes assertions along the same line. The author writes: "I assume that assertion expresses not one, but two commitments. In asserting a proposition, the speaker first expresses a commitment to the proposition, and then the speaker calls on the addressee to be also committed to that proposition, with the result that the proposition becomes part of the common ground". This two-stage process appears clearly in the analysis of confirmation requests, for which Beyssade and Marandin have shown that the requests have to be distinguished both from assertions and from questions. If we consider the utterance "Jean est malade, n'est-ce pas?" or its English counterpart "John is ill, isn't he?", we assume that it triggers two updates: firstly S's commitment to the proposition that John is ill, and secondly the expectation expressed by the speaker that the addressee takes on board the question "Is John ill?" and uses the next move to answer this question. Thus, intonational contours, like tags, specifically contribute to this second and very important aspect of speech acts, which has to do with what attitude the speaker attributes to the addressee and what he/she expects from the addressee.

As illustrated in Fig. 3, Beyssade and Marandin (2007) organized the meaning of French tunes within a two-level hierarchical structure. At the first level, a falling contour contrasts with non-falling contours through the attribution of attitude to $A$ by $S$ since the choice by $S$ of a fall conveys that A would potentially agree with S's viewpoint while his/her choice of a non-falling contour conveys on the contrary that A would potentially disagree with it. At a second level, a rising contour contrasts with a rise-fall from a penultimate peak contour on the commitment dimension since a rise conveys S's 


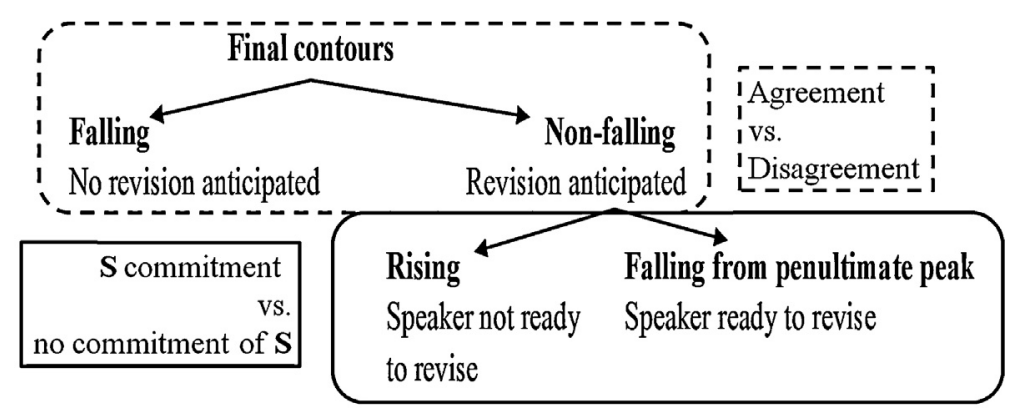

Fig. 3. Beyssade and Marandin's model of French intonational meaning. The first level of contrast concerns attitude attribution (agreement versus disagreement, framed by full lines). The second level of contrast refers to commitment (S's commitment versus the absence of S's commitment, framed by dotted lines).

commitment while a rise-fall from penultimate conveys S's openness to the revision of his/her beliefs. In sum, French tunes make both S's commitments and S's belief about A's belief public.

The present study builds on this idea, that intonational meaning is crucially dialogical and conveys S's commitment, the attribution of attitudes to A by S, and S'S call on A. If these hypotheses are true, it should be possible to determine experimentally whether intonational contours convey S's attitude toward the local embedding of his move in the ongoing interaction. Indeed, if speaking is a dialogical activity whereby both $S$ and $A$ track their interlocutor's knowledge and belief (Clark, 1996), A's reaction to the utterance should reflect S's announcements about A's potential disagreement and commitment.

\section{Interpretation experiment}

\subsection{Objectives and general method}

To date, the idea that French intonational meaning is crucially dialogical and relies on speaker commitment, attribution of attitudes and call on addressee has been developed in theoretical work (Beyssade and Marandin, 2007; Portes and Reyle, 2014; Portes and Beyssade, in press) and observed in conversational data in a radio debate corpus (Portes, 2004). However, it has never been tested experimentally.

The design of the present experiment is based on a view that is now commonly accepted among studies of conversation/dialogue: let a speaker $\mathrm{S}$ and his/her addressee $\mathrm{A}$ be engaged in conversation. When $\mathrm{S}$ addresses his/her turn $t$ to $A$, A's reaction to $t$ shows how he/she apprehends S's turn. The apprehending here ranges from attention to comprehension and uptake (following Clark's (1996) four levels of conversation). In particular, when A does not disagree with S's turn, he/she may be quick to commit to its content, without explicit acknowledgment, or he/she may comment on it. This latter case is known as making an 'account' in the tradition of Conversation Analysis. This is the dialogue routine we used in our experiment.

Participants were asked to behave as if they were in dialogue. They listened to a turn addressed to them. The turn featured one of the four contours under study. Participants had to react by using a reaction among a fixed set of four reactions. Each reaction correlated with a contour as an appropriate description of the dialogue state required by the uptake of the speaker's turn, given the contour.

Our aim was to capture the distinctive features of the prototypical meanings associated with the four contours under study. We assumed that specific participants' reactions reflect how they interpret the contours and how they react as addressees to the speaker's attribution of attitudes to them and to the speaker's call on addressee.

\subsection{Hypothesis on contour-reaction pairing}

In keeping with the theoretical developments mentioned in section 4.1 above, we hypothesized the following contourreaction pairing. By using the fall $L * \%, S$ presents him/herself as committed to the content of the utterance and presents this content as uncontroversial for A, i.e. easy to add to their common ground, as proposed by Beyssade and Marandin (2007). If this is the case, a possible reaction of A could then be 'J'en prends note' I get it signaling that the content is actually added to the common ground (CG). With such a reply, A conforms to S's projection that $A$ has no reason to reject or discuss the content of the utterance and that $A$ would add it directly to the CG. A second hypothesis is that, using the simple rise $\mathrm{H}^{*} \mathrm{H} \%$, S presents A as potentially committed to the content $p$ or to its negation $\neg p$. In this case, an appropriate reaction could be 'J'en sais rien', ('ve no idea) which contradicts S's belief on A's potential commitment, showing that S's expectation is precisely that A may or 
Table 1

Hypothesized contour-reaction pairing tested in the forced-choice interpretation task.

\begin{tabular}{|c|c|c|}
\hline Contour & Prototypical meaning features & Reaction \\
\hline$L^{*} L \%$ & $\begin{array}{l}S \text { commits him/herself to the truth of } p \\
S \text { signals that he/she anticipates no disagreement from A (about } p \text { ) } \\
S \text { proposes to } A \text { to update CG with } p\end{array}$ & $\begin{array}{l}\text { J'en prends note } \\
\text { I get it } \\
\text { A acknowledges that } S \text { has no disagreement } \\
\text { about } p \text { and that } p \text { can be added to the } C G\end{array}$ \\
\hline $\mathrm{H}^{*} \mathrm{H} \%$ & $\begin{array}{l}S \text { signals that he/she doesn't commit to } p \\
S \text { signals that he/she attributes a belief about } p \text { to } A \text { (that } p \text { or not } p \text { ) } \\
S \text { proposes to } A \text { to commit to } p \text { or to commit to not } p\end{array}$ & $\begin{array}{l}\text { J'en sais rien } \\
\text { I've no idea } \\
\text { Contradicts S's attribution to A }\end{array}$ \\
\hline$H^{*} L \%$ & $\begin{array}{l}S \text { commits him/herself to } p \\
S \text { signals that he/she anticipates a disagreement from } A: S \text { signals that he/she } \\
\text { attributes to } A \text { the belief that not } p \text {. } \\
S \text { proposes to } A \text { to update CG with } p\end{array}$ & $\begin{array}{l}\text { Tu dois avoir raison } \\
\text { I guess you're right } \\
\text { Acknowledgment of S's commitment } \\
\text { Remaining potential disagreement of } A\end{array}$ \\
\hline $\mathrm{H}+! \mathrm{H}^{*} \mathrm{H} \%$ & $\begin{array}{l}S \text { signals that he/she does not commit to } p \\
S \text { signals that he/she anticipates a disagreement from } A: S \text { signals that he/she } \\
\text { attributes to } A \text { the belief that } p \\
S \text { proposes to } A \text { either to commit to } p \text { or to commit to not } p\end{array}$ & $\begin{array}{l}\mathrm{Si}, \mathbf{s i} \text {, je t'assure } \\
\text { No, really, it's true } \\
\text { Comments both on S's disagreement and } \\
\text { on the confirmed commitment of A }\end{array}$ \\
\hline
\end{tabular}

may not believe $p$ to be true. Asking a confirmation question about $p$ (here using the contour $H^{*} H \%$ ) to an addressee $A$, is appropriate if the speaker makes the hypothesis that $A$ should give him the answer. This is the case if $A$ knows whether $p$ or $\neg$ p. By using the reaction 'l've no idea', A informs the speaker that he is wrong making this hypothesis. Concerning the $H^{*} L \%$ rising-falling contour, we hypothesized that it conveys the potential disagreement of A as well as a strong commitment on S's behalf. A possible reaction could be 'Tu dois avoir raison' (I guess you're right), which conveys both the acknowledgment of S's commitment and some remaining doubt on A's behalf, concerning the content of the utterance. Finally, the rise-fall-rise $\mathrm{H}+! \mathrm{H}^{*} \mathrm{H} \%$ would present the content as extremely doubtful for $\mathrm{S}$ but supported by $\mathrm{A}$. In this case, the reaction ' $\mathrm{Si}$, si, je t'assure' (No, really, it's true) would comment both on the doubt of $S$ and on the strong commitment of $A$. Our hypotheses on contour-reaction pairing are summarized in Table 1.

\subsection{Speech material}

\subsubsection{Sentences}

Twelve target sentences were constructed as carriers for the four intonational contours under study (the twelve sentences are provided in Appendix A below). Each sentence presented a Subject-Verb-Object (SVO) word order. They all contained a subject consisting of a one-syllable first name, a four-syllable transitive verb made up of a one-syllable auxiliary and a three-syllable past participle, and a four-syllable object made up of a one syllable determinant and a threesyllable noun, as shown in example (1) below.

(1) [Yves]S [a revendu]V [le mobilier]O

1 syl $1 \mathrm{syl}+3 \mathrm{syl} \quad 1 \mathrm{syl}+3 \mathrm{syl}$

Yves has sold the furniture

All sentences were voiced throughout, so as to avoid any disruption of the f0 contours. This was done to ensure that all the contours of the same types were identical in all the twelve target sentences.

\subsubsection{Contour production}

Each of the twelve target sentences was produced using the four contours by the same female French native speaker (who is also an expert in prosody and the first author of this paper) thus providing the 48 auditory stimuli to be used in the experiment. The sentences were read while eliciting the contours and focusing on the meaning of each contour. For each target sentence, one utterance was produced as a statement in answer to a question (e.g. 'Qu'est-ce qui s'est passé pendant mon absence?' What happened while I was away?), resulting in a simple falling contour $\mathrm{L}^{*} \mathrm{~L} \%$. The second version of each sentence was produced as a yes-no question. Here the resulting f0 contour was made up of a simple rise $\mathrm{H}^{*} \mathrm{H} \%$. Then, the third version of each sentence was produced with the speaker implying strong commitment to what she was saying and anticipating potential disagreement by the addressee, in order to obtain a rising-falling contour $\mathrm{H}^{*} \mathrm{~L} \%$. The final version of each sentence was produced by the speaker implying doubt about the content of the utterance while 
anticipating commitment on behalf of the addressee concerning its content. The resulting $\mathrm{H}+! \mathrm{H}^{*} \mathrm{H} \% \mathrm{fO}$ contour consisted here in a f0 peak on the penultimate syllable followed by a down-stepped high pitch accent and a high boundary tone.

The resulting 48 utterances were segmented and saved as separate files. F0 curves and spectrograms were created using Praat (Boersma and Weenick, 2007). We verified that the expected prosodic phrasings (i.e. three APs and one IP) and target intonational contours were actually produced by the speaker. To do so, intonational contours associated with the IP-final APs were manually annotated through a ToBI-style annotation scheme inspired by Jun and Fougeron's $(2000,2002)$ and Post's (2000) proposals. The results of the annotation revealed that all sentences were produced with the expected IP-final contours, as illustrated in Fig. 2 (see section 2 above).

Four groups of experimental utterances were constructed so that only one example for four of each of the twelve carrier-sentences appeared in each block. Hence, each group contained sentences associated to the four different target contours. For each group, the order of appearance of possible reactions was randomized. Since participants were exposed to only one group, this design allowed us to make sure that each participant heard only one member of each quartet of utterances. Reactions were also presented in a random order. Within each group the order of presentation of trials was also randomized and different for each participant.

\subsubsection{Validation of the stimuli}

We checked both the auditory discrimination between the four contours under investigation and the plausibility of the sentence-reaction pairs out of any prosodic shaping.

First, we checked whether the listeners could discriminate the four target intonational contours. In order to do so, we asked 20 French native-speakers to take part in a discrimination task. The average age of the participants was 28 $(S D=8.2)$. All participants were born in France. They were asked to judge whether the two stimuli they heard were identical or different. The stimuli were presented via binaural headphones. Each target contour could be paired with itself ('target contour') or with one of the three other possible contours ('other contours'). For half of the participants the target contour was placed first, for the other half it was placed in second position. Two lists of sentences were constructed. Each list contained 96 experimental trials (with all the four target contours and all the four other contours) and 96 fillers for a total of 192 trials. Among the 96 pairs of fillers, 24 were segmentally identical but differed regarding their intonation contours and 72 were strictly identical regarding both their segmental and intonation structures. The 192 trials were run in a random order for each participant and no one sentence appeared twice in succession. A series of exact binomial tests showed that participants gave significantly more correct responses than incorrect responses for all contours (all p's < 0.001). Hence, all the four contours under investigation were very clearly discriminated from one another.

We also checked whether the four reactions were plausible with each target utterance apart from influence of prosody. To do so, we asked a group of 40 French participants to read all the sentences paired with one of the four possible reactions. The average age of the participants was $26.5(S D=2.3)$. All participants were born in France. They judged the plausibility of the exchange (utterance + reaction) on a 7 point-Likert scale $(0=$ completely implausible, $7=$ highly plausible). A Latinsquare design was used to ensure that participants judged only one possible reaction for each experimental utterance. The average plausibility was 5.27 for the 'I get it' reaction ( $L^{*} L \%$ reaction), 3.83 for the 'I've no idea' reaction $\left(H^{*} H \%\right.$ reaction), 3.745 for the 'I guess you're right' reaction ( $\mathrm{H}^{*} \mathrm{~L} \%$ reaction) and 3.43 for the ' $\mathrm{No}$, really, it's true' reaction $\left(\mathrm{H}+! \mathrm{H}{ }^{*} \mathrm{H} \%\right.$ reaction). The $L^{*} L \%$ responses were judged more plausible than other reactions (than $\mathrm{H}^{*} \mathrm{H} \%$ reactions: $t(217)=5.75, p<0.01$, than $\mathrm{H}^{*} \mathrm{~L} \%$ reactions: $t(234)=5.76, p<0.01$, than $\mathrm{H}+! \mathrm{H}^{*} \mathrm{H} \%$ reactions: $t(238)=7.0, p<0.01$ ). Reaction occurrence probabilities depending on utterances may thus contribute to favor the selection of the $L * L \%$ reaction over other reactions.

\subsection{Procedure}

Eighty native French speakers took part in the experiment. They all had a university degree. The average age of the participants was $21.12(\mathrm{SD}=2.28)$. All participants were born in France.

Each participant was tested individually in a sound proof room. Stimuli were delivered via headphones at a comfortable listening level of approximately $70 \mathrm{~dB}$. The whole experimental procedure was controlled using E-prime. The target sentence was presented orally, with no written aids, so as to ensure intonation plays a major part in the interpretation process. The screen was left blank for 200 milliseconds then the four possible reactions appeared in written form on the screen. Each reaction was associated with a color button and participants had to press the corresponding button of a button box. Before the experiment began, the participants received 6 practice trials (see Appendix $B$ below). We recorded the type of response given by each participant.

\subsection{Results}

Fig. 4 depicts how many times each reaction was chosen, and for each of the four intonational contours. Reactions were coded according to hypothesized contour-reaction pairing: reaction "J'en prends note" I get it was coded r_L* $L \%$ since it is 


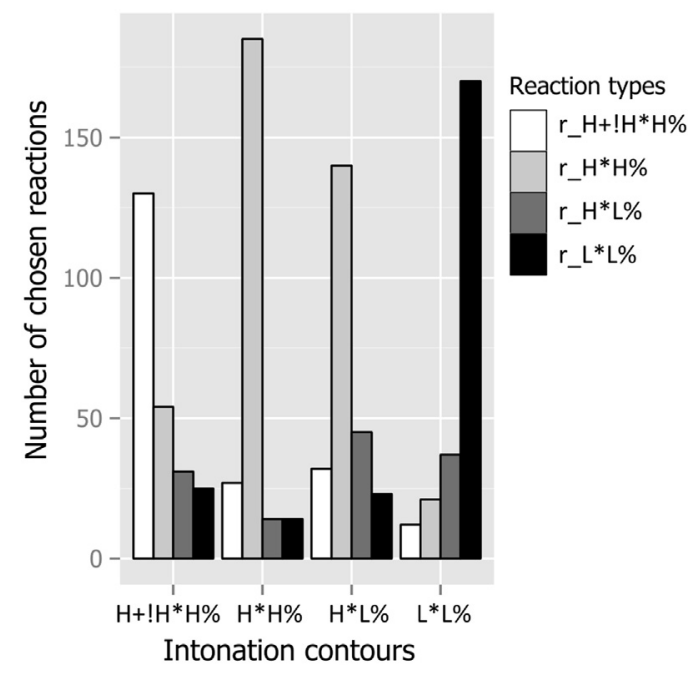

Fig. 4. Number of each type of reactions by intonational contour.

paired with $L^{*} \mathrm{~L} \%$, reaction "J'en sais rien" /'ve no idea was coded $\mathrm{r}_{-} \mathrm{H}^{*} \mathrm{H} \%$ since it is paired with $\mathrm{H}^{*} \mathrm{H} \%$, reaction "Tu dois avoir raison" I guess you're right was coded $\mathrm{r}_{-} \mathrm{H}^{*} \mathrm{~L} \%$ and reaction " $\mathrm{Si}$, si, je t'assure" $N o$, really, it's true was coded r_H+! $\mathrm{H}^{*} \mathrm{H} \%$.

Fig. 4 indicates that reaction $r_{-} L^{*} L \%$ was more often chosen with contour $L^{*} L \%$, that $r_{-} H^{*} H \%$ was more often chosen with contour $\mathrm{H}^{*} \mathrm{H} \%$ and that $r_{-} \mathrm{H}+! \mathrm{H}^{*} \mathrm{H} \%$ was more often chosen with contour $\mathrm{H}+! \mathrm{H}^{*} \mathrm{H} \%$. Conversely, contour $\mathrm{H}^{*} \mathrm{~L} \%$ is not directly linked with its hypothesized reaction since $r_{-} H^{*} H \%$ was the most common response to $H^{*} L \%$ before $r_{-} H^{*} L \%$.

In order to model the effects of the presentation of the various contours on the probabilities of observing each of the four possible reactions, we used a multinomial mixed effects logistic model, as implemented through the MCMCGImm package (Hadfield, 2010) for the R software (R Development Core Team, 2005).

The multinomial categorical dependent variables corresponding to participants' responses were coded using four possible binomial variables, one for each possible reaction. Therefore, for each observed reaction, if the participant's choice is for example $r_{-} H^{*} L \%$, the corresponding binomial variable has value 1 , while all the other variables have value 0 . We set as baseline probability level, the probability of observing an $r_{-} \mathrm{H}^{*} \mathrm{~L} \%$ reaction after the presentation of an $\mathrm{H}^{*} \mathrm{~L} \%$ contour. This model allowed us to test: (1) whether the probability of observing the baseline reaction $\left(r_{-} H^{*} L \%\right)$ on presentation of the baseline contour $\left(\mathrm{H}^{*} \mathrm{~L} \%\right)$ was different from the probability of observing any other reaction when that same contour was presented; (2) whether the differences between the probability of observing the baseline reaction $\left(r_{-} H^{*} L \%\right)$ and the probability of observing each other reaction $\left(r_{-} L^{*} L \%, r_{-} H^{*} H \%\right.$ or $\left.r_{-} H_{+}+H^{*} H \%\right)$ changed significantly when each non-baseline contour was presented. The effects were expressed as log-odds differences from the baseline probability (the probability of observing an $r_{-} H^{*} L \%$ reaction when an $\mathrm{H}^{*} \mathrm{~L} \%$ contour was presented). We specified a maximal random effect structure (Barr et al., 2013) including a random intercept for each participant, a random intercept for each carrier sentence and random participant-contour and sentence-contour interactions. Least-informative possible priors were selected (see Hadfield, 2010, 2012, for additional details on the specification of the model and of the leastinformative priors with multiple response categorical variables). The model was run for 80,000 iterations with a burn-in phase of 15,000 interactions. In order to test the convergence of the model, we used the Raftery test (Raftery, 1995).

In Table 2 we report the estimations of the model coefficients, their standard deviation and the high and low boundaries of their highest posterior density (HPD) intervals. Significance is determined when these intervals do not cross 0 (i.e. when the $95 \%$ of the posterior distributions of the coefficient estimates, given the data, are found on the same side of the 0 value). In Table 2 the rows where the coefficients are significant are shown in bold.

This model was designed to have one intercept for each possible reaction. The coefficient relative to a reaction-specific intercept (cf. rows a-c in Table 2) indicates the log-odds difference between the probability of observing that reaction after the presentation of the contour $\mathrm{H}^{*} \mathrm{~L} \%$ and the probability of observing the reaction $r_{-} \mathrm{H}^{*} \mathrm{~L} \%$ after the presentation of that same contour.

Therefore, row (a) indicates that when the contour $\mathrm{H}^{*} \mathrm{~L} \%$ is presented, the log-odds difference between the probability of observing $r_{-} \mathrm{H}^{*} \mathrm{~L} \%$ and the probability of observing $r_{-} \mathrm{L}^{*} \mathrm{~L} \%$ is not significant (participants are no more likely to select one or the other reactions). Similarly there is no evidence that participants choose an $\mathrm{r}_{-} \mathrm{H}+! \mathrm{H}^{*} \mathrm{H} \%$ reaction more often than an $\mathrm{H}^{*} \mathrm{~L} \%$ reaction when the baseline contour is presented (row c). However as indicated in row (b), participants are more likely to choose an $r_{-} \mathrm{H}^{*} \mathrm{H} \%$ reaction than an $r_{-} \mathrm{H}^{*} L \%$ reaction when the baseline contour is presented and this difference is significant. 
Table 2

Model estimates, standard deviations and boundaries of the HPD intervals.

\begin{tabular}{|c|c|c|c|c|c|}
\hline & & Mean & SD & Low HPD bound. & High HPD bound. \\
\hline (a) & r_L*L\% & -0.2807 & 0.5809 & -1.39224 & 0.86434 \\
\hline (b) & r_H*H\% & 2.0597 & 0.5433 & 0.9711 & 3.104014 \\
\hline (c) & $\mathrm{r}_{-} \mathrm{H}+\mathrm{H}^{*} \mathrm{H} \%$ & 0.2539 & 0.5666 & -0.81271 & 1.4003 \\
\hline (d) & r_L*L\% $\times$ contour $L^{*} L \%$ & 2.6575 & 0.6729 & 1.297656 & 3.894012 \\
\hline (e) & r_ $H^{*} H \% \times$ contour $L^{*} L \%$ & -2.3877 & 0.6971 & -3.73234 & -1.0114 \\
\hline (f) & $\mathrm{r} \_\mathrm{H}+! \mathrm{H}^{*} \mathrm{H} \% \times$ contour $\mathrm{L}^{*} \mathrm{~L} \%$ & -1.2226 & 0.7292 & -2.69019 & 0.19366 \\
\hline (g) & r_L*L\% $\times$ contour $\mathrm{H}^{*} \mathrm{H} \%$ & 1.2877 & 0.8529 & -0.36397 & 2.951059 \\
\hline (h) & r_ $\mathrm{H}^{*} \mathrm{H} \% \times$ contour $\mathrm{H}^{*} \mathrm{H} \%$ & 2.32 & 0.7636 & 0.782777 & 3.745964 \\
\hline (i) & r_H+! $\mathrm{H}^{*} \mathrm{H} \% \times$ contour $\mathrm{H}^{*} \mathrm{H} \%$ & 1.682 & 0.8102 & 0.108024 & 3.255011 \\
\hline (l) & $\mathrm{r}_{-} \mathrm{L}^{*} \mathrm{~L} \% \times$ contour $\mathrm{H}+! \mathrm{H}^{*} \mathrm{H} \%$ & 0.6576 & 0.7466 & -0.82286 & 2.110092 \\
\hline (m) & r_ $\mathrm{H}^{*} \mathrm{H} \% \times$ contour $\mathrm{H}+! \mathrm{H}^{*} \mathrm{H} \%$ & -0.6347 & 0.7012 & -1.91095 & 0.84584 \\
\hline (n) & r_H+! $\mathrm{H}^{*} \mathrm{H} \% \times$ contour $\mathrm{H}+! \mathrm{H}^{*} \mathrm{H} \%$ & 2.3024 & 0.7346 & 0.894913 & 3.802208 \\
\hline
\end{tabular}

Each coefficient for an interaction between a reaction-specific intercept and the effect of a contour (rows $\mathbf{d}-\mathbf{n}$ ) indicates the changes in the log-odds difference between the probability of observing the baseline reaction and the specific reaction when, instead of the baseline contour, one of the other contours is presented.

Therefore, row $(d)$ indicates that, when presenting the contour $L^{*} L \%$, the log-odds difference between the probability of observing an $r_{-} L^{*} L \%$ reaction and the probability of observing an $r_{-} \mathrm{H}^{*} \mathrm{~L} \%$ reaction increases by 2.658 and the increase is significant. As shown in row (a), this difference was negative and non-significant when the baseline contour was presented. A positive sign for the interaction in row (d) (whose effect is nearly 10 times the effect of the response $r_{-} L^{*} L \%$ on the baseline contour) indicates that, when hearing the $L^{*} L \%$ contour the participants choose more often the $r_{-} L^{*} L \%$ reaction.

The log-odds difference between the probability of observing an $r_{-} \mathrm{H}^{*} \mathrm{H} \%$ reaction and the probability of observing an r_ $\mathrm{H}^{*} \mathrm{~L} \%$ reaction decreases significantly when participants hear the $L^{*} L \%$ contour (see row e).

Row (f) indicates that the log-odds difference between the probability of observing an $\mathrm{r}_{-} \mathrm{H}+\mathrm{H} \mathrm{H}^{*} \mathrm{H} \%$ reaction and the probability of observing an $r_{-} \mathrm{H}^{*} \mathrm{~L} \%$ reaction does not change significantly when participants hear the $\mathrm{L}^{*} \mathrm{~L} \%$ contour.

Similarly the log-odds difference between the probability of observing an r_L\% reaction and the probability of observing an $r_{-} \mathrm{H}^{*} \mathrm{~L} \%$ reaction does not change significantly when participants hear the $\mathrm{H}^{*} \mathrm{H} \%$ contour (cf. row $\mathbf{g}$ ).

However when participants hear the $\mathrm{H}^{*} \mathrm{H} \%$ contour, the log-odds difference between the probability of observing an $r_{-} \mathrm{H}^{*} \mathrm{H} \%$ reaction and the probability of observing an $r_{-} \mathrm{H}^{*} \mathrm{~L} \%$ reaction increases significantly with respect to when they hear the $\mathrm{H}^{*} \mathrm{~L} \%$ contour (cf. row $\mathbf{h}$ ). Therefore with the $\mathrm{H}^{*} \mathrm{H} \%$ contour the participants are more likely to select an $r_{-} \mathrm{H}^{*} \mathrm{H} \%$ reaction than with the baseline contour.

Row (i) indicates that when participants hear the $\mathrm{H}^{*} \mathrm{H} \%$ contour the difference between the probability of observing an r_ $\mathrm{H}+$ ! $\mathrm{H}^{*} \mathrm{H} \%$ reaction and the probability of observing an $\mathrm{r}_{-} \mathrm{H}^{*} \mathrm{~L} \%$ reaction increases significantly.

Rows $(\mathbf{I})$ and $(\boldsymbol{m})$ indicate that when the participants hear the $\mathrm{H}+! \mathrm{H}^{*} \mathrm{H} \%$ contour the log-odds differences between the probabilities of observing an $r_{-} L^{*} L \%$ reaction or an $r_{-} H^{*} H \%$ reaction and the probability of observing an $r_{-} H^{*} L \%$ reaction do not change significantly.

Finally row $(\mathbf{n})$ indicates that when the participants hear the $\mathrm{H}+! \mathrm{H}^{*} \mathrm{H} \%$ contour the log-odds difference between the probability of observing an $r_{-} \mathrm{H}_{+}+\mathrm{H}^{*} \mathrm{H} \%$ reaction and the probability of observing an $\mathrm{r}_{-} \mathrm{H}^{*} \mathrm{~L} \%$ reaction increases significantly. This means that participants are more likely to select an $r_{-} \mathrm{H}+! \mathrm{H}^{*} \mathrm{H} \%$ reaction when they hear the $\mathrm{H}^{+!} \mathrm{H}^{*} \mathrm{H} \%$ contour than when they hear the $\mathrm{H}^{*} \mathrm{~L} \%$ contour.

In summary, these results indicate that participants associates contour $L^{*} L \%$, contour $H^{*} H \%$ and contour $H+! H^{*} L \%$ with the hypothesized reactions more often than with other reactions. This does not seem to be the case for the $\mathrm{H}^{*} \mathrm{~L} \%$ contours that are more often associated with the $r_{-} \mathrm{H}^{*} \mathrm{H} \%$ reaction than with the expected $\mathrm{r}_{-} \mathrm{H}^{*} \mathrm{~L} \%$ reaction.

\section{Discussion}

As expected, the experiment shows that the participants use the reaction that is the most congruent with the associated contour, except for one of the four contours. The hypothesized reaction is selected significantly more often when $L^{*} L \%$, $\mathrm{H}^{*} \mathrm{H} \%$ and $\mathrm{H}+! \mathrm{H}+\mathrm{H} \%$ are used. Conversely, $\mathrm{H}^{*} \mathrm{~L} \%$ does not have the expected effect: it is associated with the reaction hypothesized for $\mathrm{H}^{*} \mathrm{H} \%$. Globally, these results show that our predictions concerning contour-reaction mapping were correct and give support to the claim that the proposed components of contour meanings (attribution of attitudes, commitment of $S$ and call on $A$ ) are involved in the choice of the appropriate reaction. 


\subsection{A clear pragmatic impact of the contours}

The results of the plausibility judgment (cf. section 4.3.3) have shown that the r_L*L\% reaction, i.e. "J'en prends note" I get it, were judged more plausible than the other three reactions with each target utterance apart from any influence of prosody. Conversely, the results of the interpretation task do not favor the selection of "J'en prends note" I get it, in reaction to utterances with contour. This directly underlines the impact of the contour on the interpretation: with another contour than the fall $L^{*} L \%$, participants choose another reaction than "J'en prends note" I get it.

As expected, the use of "J'en prends note" (as an ordinary account) is subject to under-specification: it could be used to comment on the uptake of the utterance (viz. adding the content to the current CG: component call on A) or to comment on the commitment of the speaker (viz. agreeing on the content $p$ : component commitment of $\mathbf{S}$ ). The comment on the uptake makes it a congruent reaction when the only resource is the phrasal type (the declarative type) and its content (a proposition). Indeed, this is shown in the plausibility test. When the contour comes into play in the interpretation task, it is no longer congruent if the contour projects either that the speaker does not take on board the propositional content (using the simple rise $\mathrm{H}^{*} \mathrm{H} \%=$ no commitment of $\mathrm{S}$ ) or that the addressee might disagree (using the rise-fall $\mathrm{H}^{*} \mathrm{~L} \%$ or the rise-fallrise $\mathrm{H}+! \mathrm{H}^{*} \mathrm{~L} \%=$ a different call on $\mathrm{A}$ ).

\subsection{The dialogical role of contours $L^{*} L \%, H^{*} H \%$ and $H+! H+H \%$}

$L^{*} L \%$ and $\mathrm{H}^{*} \mathrm{H} \%$ contours have a strong link with their expected reactions, as does $\mathrm{H}+! \mathrm{H}+\mathrm{H} \%$ contour although slightly less.

"J'en prends note" I get it has a predictably high score with the $L^{*} L \%$ falling contour. The three aspects of the utterance (phrasal, content and contour) converge to confirm the utterance as a standard assertion. In fact "J'en prends note" has proven to be an excellent means of acknowledging assertions.

The "J'en sais rien" I've no idea reaction also had an indisputable score. It is an ordinary reaction to a questioning turn: no register of any consideration is expected to interfere in participants' choice. Note that like "J'en prends note" I get it, "J'en sais rien" I've no idea can be used to comment on two different aspects. Firstly, it can comment on the uptake of the utterance (component call on addressee), turning down the question for lack of information. Secondly, it can comment on the lack of commitment of the addressee. The former could explain its high score with the $\mathrm{H}^{*} \mathrm{H} \%$ rising contour: arguably, the participants took the utterance with $\mathrm{H}^{*} \mathrm{H} \%$ as a questioning declarative: in this case, "J'en sais rien" I've no idea explicitly contradicts S's attribution to A of a knowledge about $\mathrm{p}$ (component attribution of attitude). On the other hand, the latter feature makes "J'en sais rien" I've no idea a coherent reaction to $\mathrm{H}^{*} \mathrm{~L} \%$ and, to a lesser extent, to $\mathrm{H}^{+}$! $\mathrm{H}^{*} \mathrm{H} \%$, which both project that the addressee has some knowledge about $\mathrm{p}$.

The link between the rise-fall-rise $\mathrm{H}+! \mathrm{H}^{*} \mathrm{H} \%$ and the reaction " $\mathrm{Si}$, si, je t'assure" No, really, it's true, is also clearly significant. According to our initial assumptions, the use of $\mathrm{H}+! \mathrm{H}^{*} \mathrm{H} \%$ (like the use of $\mathrm{H}^{*} \mathrm{~L} \%$ ) projects a defective context, in the sense described by Stalnaker (1978): there is a discrepancy concerning the content of the utterance between the CG as viewed by the speaker and by the addressee. The reaction "Si, si, je t'assure" No, really, it's true contains the answer "si", which is used versus "oui" in French when the preceding declarative has a negative polarity. While this is not the case of any of the twelve declaratives used in the experiment, the relevance of this reaction shows that "si" in "Si, si, je t'assure" does not refer to the proposition expressed by the sentence but by its negation by $\mathrm{S}$ conveyed by the $\mathrm{H}+! \mathrm{H}^{*} \mathrm{H} \%$ contour (component speaker commitment). This is because $\mathrm{H}+! \mathrm{H}^{*} \mathrm{H} \%$ both signals that $S$ does not commit to $\mathrm{p}$ (and then commits to not p) and that he/she attributes to A the belief that $\mathrm{p}$. As for "je t'assure" in the reaction "Si, si, je t'assure", it confirms that the addressee is indeed committed to $p$, as conveyed by the contour (component attribution of attitude).

Therefore, for the three contours $\mathrm{L}^{*} \mathrm{~L} \%, \mathrm{H}^{*} \mathrm{H} \%$ and $\mathrm{H}+\mathrm{H}+\mathrm{H} \%$, the participants' behavior quite clearly confirmed our hypotheses concerning these contours prototypical meanings and the relevance of the dialogical components speaker commitment, attitude attribution and call on addressee to account for them.

However, the experiment failed to confirm our hypothesis concerning $\mathrm{H}^{*} \mathrm{~L} \%$.

\subsection{The case of $H^{*} L \%$}

The link between the rise-fall $\mathrm{H}^{*} \mathrm{~L} \%$ and the expected reaction "Tu dois avoir raison" I guess you're right is not confirmed by our participants. Instead, they very consistently pair $\mathrm{H}^{*} \mathrm{~L} \%$ with the reaction "J'en sais rien" l've no idea. Several explanations could be proposed.

Firstly, as we already mentioned in section 5.2 above, "J'en sais rien" l've no idea is a coherent reaction to H* $\mathrm{L} \%$ : this contour projects that the addressee has some knowledge about $p$ since it signals that $S$ believes that $A$ does not believe $p$. In this respect, the reaction "J'en sais rien" I don't know that we chose was not specific enough to disentangle the rise $\mathrm{H}^{*} \mathrm{H}$ $\%$ from the rise-fall $\mathrm{H}^{*} \mathrm{~L} \%$, even if the link is far stronger for $\mathrm{H}^{*} \mathrm{H} \%$. In this respect, the contour-reaction paradigm that we propose here should be refined in future work, in order to find more distinctive pairs for contour-reaction pairing. 
Second, the rise-fall $H^{*} \mathrm{~L} \%$ has often been associated with the notions of "expressiveness", "emphasis" or "emotion". Thus, Rossi (1999) called this contour "expressème", Di Cristo and Hirst (1996) talked about "l'emphase contrastive" (contrastive emphasis) and Bagou's work (2001) is about "l'implication emphatique" (emphatic implication). Therefore, it could be that the very impersonal context of the experiment penalized the prototypical meaning of $\mathrm{H}^{\star} \mathrm{L} \%$.

Finally, we said that the use of the rise-fall $\mathrm{H}^{*} \mathrm{~L} \%$, like the use of the rise-fall-rise $\mathrm{H}+! \mathrm{H}^{*} \mathrm{H} \%$, projects a defective context. But while a defective context may be systematic in the case of $\mathrm{H}+! \mathrm{H}^{\star} \mathrm{H} \%$, since the contour conveys that the speaker him/ herself does not agree with the content of the utterance, it could be more variable in the case of $\mathrm{H}^{\star} \mathrm{L} \%$. For instance, in a study testing the meaning of $\mathrm{H}^{*} \mathrm{~L} \%$ against empirical verification in corpus data, Portes and Reyle (2014) found that if most of their corpus occurrences of $\mathrm{H}^{*} \mathrm{~L} \%$ indeed appear in defective contexts, some of them do not, i.e. when a set of alternatives to $\mathrm{p}$ was preserved in the context. For instance, items in which the speaker directly contradicted or corrected the addressee's preceding move are clear cases of defective uses of $\mathrm{H}^{*} \mathrm{~L} \%$; on the other hand, it was enough that the utterance referred to one element of a set of alternatives that was active in the context (a curtain among other things at the window) to allow its bearing $\mathrm{H}^{*} \mathrm{~L} \%$ (see Portes and Reyle, 2014 for details and corpus examples). Thus, the interpretation of $\mathrm{H}^{*} \mathrm{~L} \%$ may be more sensitive to various contextual factors than the other three contours. More studies on this contour, its contexts of appearance and meanings are necessary to define its precise place and role in the dialogical inventory of French tunes.

\subsection{Further comments and perspectives}

First, the present study crucially relies on the idea that "pragmatics is the study of those relations between language and context that are grammaticalized, or encoded in the structure of language" (Levinson, 1983:9), or, in other words that "linguistic design is inextricably linked to interactional functions, and that the former cannot be fully understood without consideration of the latter" (Persson, 2013:19). Hence, the design we used for this experiment is original as it relies on the skill of the speakers as dialogue participants. We did not know in advance whether the participants would adjust easily to the design of the experiment or whether it would yield a coherent pattern of results. Eventually, however, it did show coherent results, and in so doing strengthens a dialogical approach to intonational meaning based on the idea that intonation integrates a recipient design (Sacks and Schegloff, 1974) or audience design (Clark and Carlson, 1982) as one of its main active components. This means that at least some part of intonational meaning involves the co-participants in the interaction. Among the three components of intonational meaning explored in the study, two are undoubtedly oriented as proposed by the notion of recipient design: attribution of intention (or belief, or knowledge) to $A$ and call on $A$. The results we obtained are very much in keeping with our initial hypothesis that participants react to the commitment or the dialogical move that the contour projects for them to take up. Thus, we conclude that this is a suitable design, not only to study the meaning of contours, but also to investigate other grammaticalized pragmatic meanings. ${ }^{2}$

Here, let us stress one of the results once again. The plausibility judgments showed that when the utterance was presented visually without prosody, the most frequent reaction was "J'en prends note" I get it. This was expected, given the declarative form of the utterance, and the prototypical link of the declarative type with an assertive move, implying that both speaker and addressee agree to commit to the same propositional content. In this experiment, the utterances were presented orally with contour and without context. Thus, it is reasonable to suggest that the participants reacted to, and interpreted, the contours per se with no contextual interference (excepting imagination, which is out of our experimental reach and control). Such a result gives support to the general hypothesis that at least part of the contours' meanings are context-free, which justifies a paradigmatic choice between a set of different intonational forms. This is in line with Gussenhoven's ‘linguistic normalcy' view (Gussenhoven, 1983) and Ladd's Linguist's Theory of Intonational Meaning (Ladd, 2008). However, as Gussenhoven (1983) underlined, meanings of most lexical morphemes adapt to context, as does intonational meaning.

We therefore conjectured that the pattern of responses to the rise-fall $\mathrm{H}^{\star} \mathrm{L} \%$ in the present study was due to the fact that the lack of context and the experimental setting did not provide enough resources for the participants to react in a natural way. This has a direct consequence on the design of experiments. Even if contour meaning is partly context-free, some features of context may afford the use of some of the contours (Marandin, 2011). Thus, it becomes relevant to control these contextual features in the experimental design. Specifically, in order to study $H^{\star} L \%$, it must be relevant to slightly modify the experimental design by adding context or content, making the use of this contours easier, and hence assisting a correct interpretation by the addressee. Experiments including a role-playing design or a game design confronting two participants in an opposing task may help to elicit emphasis in a defective context.

The conception of contour meaning, which we put to the test here, crucially involves some belief attribution mechanism. The present experiment did not enable us to directly test that aspect of belief attribution. However, it makes it

\footnotetext{
${ }^{2}$ For instance, topicalization by means of specific syntactic structures like left dislocation in French could be interestingly investigated by the same methodology.
} 
plausible to further and more directly investigate the relationship between intonational meaning and theory of mind (ToM). ToM is defined as the ability to form representations of other people's mental states and to use these representations to understand, predict and judge their statements and behaviors (Baron-Cohen et al., 1985; Premack and Woodruff, 1978). At present, little is known about the precise relationships between linguistic devices and that general cognitive ability (Champagne-Lavau et al., 2006, 2009; Michelas et al., 2014). This is especially true for intonation since research on prosody and ToM has mainly focused on its function as conveying epistemic and emotional attitudes (McCann and Peppé, 2003; Chevallier et al., 2011 for reviews) and focus marking (Michelas et al., 2014). However, the simplicity and lightness of the task and of the experimental setting proposed here will make it possible to apply the present original method and framework to populations with ToM disorders, for instance participants with schizophrenia, or autism. Specifically, French patients with ToM disorders should have more problems than control healthy participants in choosing appropriate reactions to $L^{*} L \%$ and $H^{*} H \%$. This will give access to interesting information concerning, not only the interpretative processing of prosody in ToM disordered population, but also to the consequences of the lack of access to intonational information on communicative behavior.

\section{Conclusion}

Using an original forced-choice interpretation task, the present study provides quantitative support for the view that three contours of French intonation, i.e. a simple fall $L^{*} \mathrm{~L} \%$, a simple rise $\mathrm{H}^{*} \mathrm{H} \%$ and a rise-fall-rise $\mathrm{H}+! \mathrm{H}^{*} \mathrm{H} \%$ convey dialogical meaning including speaker commitment, attitude attribution and call on addressee as its components. The results give experimental support in favor of a dialogical model of intonational meaning such as the one proposed by Beyssade and Marandin (2007) and developed by Portes and Beyssade (in press) and Portes and Reyle (2014) for French. Consequently, they also pave the way to test the conjecture that a Theory of Mind is involved in the choice of intonational contrasts by the speaker and in their interpretation by the hearer. The present study also points out the benefits of modeling some components of social interaction (here attribution of intentions to addressees) into some grammatical structures of language such as the intonational tunes as conceived by intonational phonology. We also showed that the notion of recipient design can be fruitfully adapted to a pragmatic approach of meaning components and account for dialogical dimensions of intonational meaning.

\section{Acknowledgments}

This research was supported by an Agence Nationale de la Recherche grant (ANR-11-BSH2-006-01 MINDPROGEST) to MCL. We thank Roxane Bertrand for helpful comments and are grateful to Leonardo Lancia for statistical modeling.

\section{Appendix A. Experimental sentences}

1 Jules a engagé un ingénieur

2 Louise a manœuvré le gouvernail

3 Laure a délogé le boulanger

4 Lise a arrosé les magnolias

5 Anne a adoré le mélodrame

6 Maud a ramené des vignerons

7 Yves a revendu le mobilier

8 Eve a rénové la mezzanine

9 Jeanne a emmêlé les barbelés

10 Gilles a hébergé des randonneurs

11 Dan a réouvert le magasin

12 Aude a validé les analyses

\section{Appendix B. Training sentences}

14 Marc a vérifié les procédures

15 Jacques a essayé la Chevrolet

17 Paul a réparé les robinets

18 Luc a raccourci son pantalon 


\section{References}

Bagou, Odile, 2001. Validation perceptive et réalisations acoustiques de l'implication emphatique dans la narration orale spontanée. Cahiers de linguistique française 23, 39-59.

Baron-Cohen, Simon, Leslie, Alan M., Frith, Uta, 1985. Does the autistic child have a "theory of mind"? Cognition 21 (1), 37-46.

Barr, Dale J., Levy, Roger, Scheepers, Christoph, Tily, Harry J., 2013. Random effects structure for confirmatory hypothesis testing: keep it maximal. Journal of Memory and Language 68 (3), 255-278.

Bartels, Christine, 1997. Towards a Compositional Interpretation of English Statement and Question Intonation. Ph.D. dissertation, University of Massachusetts Amherst.

Baumann, Stefan, 2006. Information structure and prosody: linguistic categories for spoken language annotation. In: Sudhoff, S., Lenertová, D., Meyer, R., Pappert, S., Augurzky, P., Mleinek, I., Richter, N., Schließer, J. (Eds.), Methods in Empirical Prosody Research, Language Context, and Cognition, vol. 3. Mouton de Gruyter, pp. 153-180.

Beyssade, Claire, Marandin, Jean-Marie, 2006. The speech act assignment problem revisited: disentangling speaker's commitment from speaker's call on addressee. In: Bonami, O., Cabredo Hofherr, P. (Eds.), Empirical Issues in Syntax and Semantics, vol. 6. pp. 37-68.

Beyssade, Claire, Marandin, Jean-Marie, 2007. French intonation and attitude attribution. In: Denis, P., McCready, E., Palmer, A., Reese, B. (Eds.), Proceedings of the 2004 Texas Linguistics Society Conference: Issues at the Semantics-Pragmatics Interface.

Beyssade, Claire, Marandin, Jean-Marie, 2009. Commitment: une attitude dialogique. Langue Française 162, 89-107.

Beyssade, Claire, Hemforth, Barbara, Marandin, Jean-Marie, Portes, Cristel, 2011. Prosodic markings of information focus in French. In: Yoo, Y., Delais-Roussarie, E. (Eds.), Proceedings of the conference "Interface Discours and Prosodie", Paris, France, pp. 109-122.

Boersma, Paul, Weenick, David, 2007. Praat: doing phonetics by computer (Version 4.5.18). http://praat.org/

Brazil, David, 1975, 1978. Discourse Intonation I and II. English Language Research, University of Birmingham, Birmingham.

Brazil, David, 1985. Phonology: intonation in discourse. In: Van Dijk, T.A. (Ed.), Handbook of Discourse Analysis 2: Dimensions of Discourse. Academic Press.

Champagne-Lavau, Maud, Stip, Emmanuel, Joanette, Yves, 2006. Social cognition deficit in schizophrenia: accounting for pragmatic deficits in communication abilities? Current Psychiatry Reviews 2 (3), 309-315.

Champagne-Lavau, Maud, Fossard, Marion, Martel, Guillaume, Chapdelaine, Cimon, Blouin, Guy, Rodriguez, Jean-Pierre, et al., 2009. Do patients with schizophrenia attribute mental states in a referential communication task? Cognitive Neuropsychiatry 14 (3), $217-239$.

Chevallier, Coralie, Noveck, Ira, Happé, Francesca, Wilson, Deirdre, 2011. What's in a voice? Prosody as a test case for the Theory of Mind account of autism. Neuropsychologia 49, 507-517.

Clark, Herbert H., 1992. Arenas of Language Use. The University of Chicago Press, Chicago, IL.

Clark, Herbert H., 1996. Using Language. Cambridge University Press.

Clark, Herbert H., Carlson, T.B., 1982. Hearers and speech acts. Language 58, 332-373.

Clark, Herbert H., Marshall, Catherine, R., 1981. Definite reference and mutual knowledge. In: Joshi, A., Webber, B., Sag, I. (Eds.), Elements of Discourse Understanding. Cambridge University Press, Cambridge, pp. 10-63.

Delattre, Pierre, 1966. Les dix intonations de base du français. French Review 40.

Dell, François, 1984. L'accentuation dans les phrases en français. In: Dell, F., Hirst, D., Vergnaud, J.-R. (Eds.), Forme Sonore du Langage. Hermann, Paris, pp. 65-122.

Di Cristo, Albert, 1999. Vers une modélisation de l'accentuation en français. Première partie: la problématique. Journal of French Language Studies 9, 143-179.

Di Cristo, Albert, Hirst, Daniel, 1996. Vers une typologie des unites intonatives du français. In: Société française d'acoustique (Eds.), 16émes Journées d'Etude sur la parole. Avignon, pp. 219-222.

Faure, George, 1973. La description phonologique des systèmes prosodiques. Studia Phonetica 8, 1-16.

Féry, Caroline, 2001. The phonology of focus in French. In: Féry, C., Sternefeld, W. (Eds.), Audiatur Vox Sapientiae. A Festschrift for Arnim von Stechow. Akademie-Verlag, Berlin, pp. 153-181.

Féry, Caroline, 2013. Focus as prosodic alignment. Natural Language Linguistic Theory 31.2. http://dx.doi.org/10.1007/s11049-013-9195-7

Gazdar, Gerald, 1981. Speech act assignment. In: Joshi, Webber, Sag, I. (Eds.), Elements of Discourse Understanding. Cambridge University Press, pp. 64-83.

German, James, D'Imperio, Mariapaola, 2010. Focus, phrase length, and the distribution of phrase-initial rises in French. In: Proceedings of the International Conference on Speech Prosody, Chicago, USA.

Grammont, Maurice, 1933. Traité de phonétique. Delagrave, Paris.

Grice, H. Paul, 1975. Logic and conversation. In: Cole, P., Morgan, J.L. (Eds.), Syntax and Semantics III: Speech Acts. Academic Press, New York, pp. 41-58.

Grice, Martine, Savino, Michelina, 1997. Can pitch accent type convey information-status in yes-no questions? In: Proceedings of ACL 97 Workshop on Concept to Speech Generation Systems, Madrid, Spain, pp. 29-38.

Gunlogson, Christine, 2003. True to Form: Rising and Falling Declaratives as Questions in English. PhD Thesis, Routledge, New York, 2001, published in 2003.

Gunlogson, Christine, 2008. A question of commitment. In: De Brabanter, P., Dendale, P. (Eds.), Commitment, pp. 101-136.

Gussenhoven, Carlos, 1983. A semantic analysis of the nuclear tones in English. In: Gussenhoven, C. (Ed.), On the Grammar and Semantics of Sentence Accents. Foris, Dordrecht, Netherlands, pp. 193-267.

Hadfield, Jarrod D., 2010. MCMC methods for multi-response generalized linear mixed models: the MCMCgImm R package. Journal of Statistical Software 33 (2), 1-22.

Hadfield, Jarrod D., 2012. MCMCglmm course notes. Available from http://cran.us.rproject.org/web/packages/MCMCglmm/vignettes/Course Notes.pdf.

Hamblin, Charles L., 1970. Fallacies. Methuen, London. 
Hamblin, Charles L., 1971. Mathematical models of dialogue. Theoria 37, 130-155.

Hirschberg, Julia, 2003. Pragmatics and intonation. In: Horn, L., Ward, G. (Eds.), Handbook of Pragmatics. Blackwell, New York, pp. 515-537.

Hirschberg, Julia, Ward, Gregory, 1992. The influence of pitch range, duration, amplitude and spectral features on the interpretation of the rise-fallrise intonation contour in English. Journal of Phonetics 20, 241-251.

Hirschberg, Julia, Ward, Gregory, 1995. The interpretation of the high-rise question contour in English. Journal of Pragmatics 24 (5), $407-412$.

Jun, Sun-Ah, Fougeron, Cécile, 2000. A phonological model of French intonation. In: Botinis, A. (Ed.), Intonation: Analysis, Modelling and Technology. Kluwer, Boston.

Jun, Sun-Ah, Fougeron, Cécile, 2002. Realizations of accentual phrase in French. Probus 14, 147-172.

Krifka, Manfred, 2014. Negated polarity questions as denegations of assertions. In: Kiefer, F., Lee, C. (Eds.), Contrastiveness and Scalar Implicatures. Springer (in press).

Ladd, Robert D., 1996, 2008. Intonational Phonology. Cambridge University Press, Cambridge.

Leon, Pierre, 1992. Phonétisme et prononciation du français. Nathan, Paris.

Levinson, Stephen C., 1983. Pragmatics. Cambridge University Press, Cambridge.

Liberman, Mark, Sag, Ivan, 1974. Prosodic form and discourse function. CLS 10, 416-427.

Marandin, Jean-Marie, 2011. Affordance and ability. How do participants replicate linguistic choices in the lab? Belgian Journal of linguistics 25 , 30-50.

Martin, Philippe, 1975. Analyse phonologique de la phrase française. Linguistics 146, 35-67.

McCann, Joanne, Peppé, Sue, 2003. Prosody in autism spectrum disorders: a critical review. International Journal of Language and Communication Disorder 38 (4), 325-350.

Merin, Arthur, Bartels, Christine, 1997. Decision-theoretic Semantics for Intonation. Manuscript, University of Stuttgart and University of Oregon.

Mertens, Piet, 1990. Intonation. In: Blanche-Benveniste, C., Bilger, M., Rouget, C., van den Eynde, K. (Eds.), Le Français parlé. CNRS Éditions, Paris, pp. 159-176.

Mertens, Piet, 2008. Syntaxe, prosodie et structure informationnelle: une approche prédictive pour l'analyse de l'intonation dans le discours. Travaux de Linguistique 56 (1), 87-124.

Michelas, Amandine, Faget, Cathrine, Portes, Cristel, Lienhart, Anne-Sophie, Boyer, Laurent, Lançon, Christophe, Champagne-Lavau, Maud, 2014. Do patients with schizophrenia use prosody to encode constrative discourse status? Frontiers in Psychology 5 Article 755 , http://dx.doi. org/10.3389/fpsyg.2014.00755.

Michelas, Amandine, Portes, Cristel, Champagne-Lavau, Maud, 2014. When pitch accents encode speaker commitment: evidence from French intonation. Language and Speech (in press).

O’Connor, John D., Arnold, Gordon K., 1973. Intonation of Colloquial English. Longman, London.

Persson, Rasmus, 2013. Intonation and sequential organization: formulations in French talk-in-interaction. Journal of Pragmatics 57, $19-38$.

Pierrehumbert, Janet, Hirschberg, Julia, 1990. The meaning of intonation in the interpretation of discourse. In: Cohen, P., Morgan, J., Pollack, M. (Eds.), Intentions in Communication. MIT Press, Cambridge, MA, pp. 271-311.

Portes, Cristel, 2004. Prosodie et économie du discours: Spécificité phonétique, écologie discursive et portée pragmatique de l'intonation d'implication. PhD thesis, Aix-Marseille Université.

Portes, Cristel, Beyssade, Claire, 2015. Is intonational meaning compositional? Verbum (in press).

Portes, Cristel, Reyle, Uwe, 2014. The meaning of French "implication" contour in conversation. In: Proceedings of Speech Prosody 2014, Dublin, Ireland, 20-23 May 2014.

Post, Brechtje, 2000. Tonal and phrasal structures in French intonation. Published PhD dissertation, Holland Academic Graphics, The Hague.

Premack, David, Woodruff, Guy, 1978. Does the chimpanzee have a theory of mind? Behavioral and Brain Sciences 4, 515-526.

R Development Core Team, 2005. R: A Language and Environment for Statistical Computing, Reference Index Version 2.2.1. R Foundation for Statistical Computing, Vienna, Austria, http://www.R-project.org

Raftery, Adrian E., 1995. Bayesian model selection in social research. Sociological Methodology 25, 111-164.

Rossi, Mario, 1980. Le français, langue sans accent? In: Fónagy, I., Léon, P. (Eds.), L'accent en français contemporain. Didier, Montréal, Studia Phonetica 15, 13-51.

Rossi, Mario, 1981. Vers une théorie de l'intonation. In: Rossi, M., Di Cristo, A., Hirst, D., Martin, P., Nishinuma, Y. (Eds.), L'intonation: de l'acoustique à la sémantique. Klincksieck, Paris.

Rossi, Mario, 1999. L'intonation, le système du français: description et modélisation. Ophrys.

Sacks, Harvey, Schegloff, Emanuel, 1974. A simplest systematics for the organization of turn-taking for conversation. Language 50, 696-735.

Stalnaker, Robert, 1978. Assertion. Pragmatics, Syntax and Semantics 9.

Steedman, Mark, 2007. Information-structural semantics for English intonation. In: Lee, C., Gordon, M., Büring, D. (Eds.), Topic and Focus: Crosslinguistic Perspectives on Meaning and Intonation. Dordrecht, Springer, pp. 245-264.

Truckenbrodt, Hubert, 2004. Sentence-type Meanings. Ms, Universität Tübingen.

Vaissière, Jacqueline, 1980. La structuration acoustique de la phrase française. In: Pacini-Mariotti (Eds.), Annali Della Scuola ormale Superiore Di Pisa. Tipografia, Pisa, pp. 530-560.

Vaissière, Jacqueline, 1983. Language-independent prosodic features. In: Cutler, A., Ladd, R. (Eds.), Prosody: Models and Measurements. Springer Verlag, Berlin, pp. 53-66.

Vanrell, Maria del Mar, Mascaró, Ignasi, Torres-Tamarit, Francesco, Prieto, Pilar, 2013. Intonation as an encoder of speaker's certainty: information and confirmation yes-no questions in Catalan. Language and Speech 56 (2), 163-190.

Ward, Gregory, Hirschberg, Julia, 1985. Implicating uncertainty: the pragmatics of fall-rise intonation. Language 64-1, 747-776. 